\title{
INFLUÊNCIA DE DIFERENTES SISTEMAS DE COLHEITA NA QUALIDADE DO CAFÉ (Coffea arabica L.) ${ }^{1}$
}

\author{
CÁSSIO DE CARVALHO JÚNIOR ${ }^{2}$ \\ FLÁVIO MEIRA BORÉM ${ }^{3}$ \\ ROSEMARY G. F. ALVARENGA PEREIRA ${ }^{4}$ \\ FÁBIO MOREIRA DA SILVA
}

\begin{abstract}
RESUMO - Com o objetivo de avaliar a influência da colheita na qualidade do café, foram estudados seis diferentes sistemas. $\mathrm{O}$ experimento foi conduzido na Fazenda Rancho Fundo, município de Campos Gerais, MG, no Departamento de Ciência dos Alimentos da UFLA e no Centro Tecnológico do Sul de Minas da EPAMIG. Em uma lavoura da cultivar Acaiá Cerrado, foram sorteadas, ao acaso, dezoito parcelas com trinta metros de comprimento. A colheita foi realizada quando a lavoura apresentava aproximadamente $20 \%$ de frutos verdes. Um terço do café derriçado de cada parcela era formado pela mistura de frutos provenientes da lavoura. O restante do café foi lavado e separado em frutos-bóia e verde/cereja. Os diferentes tipos de café foram colocados no
\end{abstract}

TERMOS PARA INDEXAÇÃO: Café, derriçadoras, composição química.

terreiro de secagem até atingirem o teor de água de $11 \%$ (b.u.). Após a secagem, o café foi beneficiado e submetido às seguintes avaliações: polifenóis, açúcares totais, redutores e não-redutores, sólidos solúveis totais, acidez titulável total e prova de xícara. Analisando os resultados obtidos, apesar de terem sido observadas diferenças significativas entre os valores médios de polifenóis, açúcares, sólidos solúveis e acidez titulável para os diferentes sistemas de colheita, não foi possível estabelecer uma associação definida entre sistema de colheita e composição química. Não foi possível também distinguir, a partir da prova de xícara, diferenças na qualidade do café em função do sistema de colheita, pois, todas as amostras analisadas apresentaram bebida classificada como mole, apenas mole e dura.

\section{INFLUENCE OF DIFFERENT HARVEST SYSTEMS ON QUALITY OF COFFEE (Coffea arabica L.)}

\begin{abstract}
Aiming to evaluating the influence of the harvest on coffee quality, six harvest systems with different mechanization level were studied. The present work was developed on the Rancho Fundo farm, Campos Gerais town, MG, in the Food Science Department of the UFLA and in the "Centro Tecnológico do Sul de Minas" of EPAMIG. In a crop of the Acaiá Cerrado cultivars were randomized eighteen plots with thirty meters long each. The harvest was performed when the crop was presenting about $20 \%$ of green fruits. A third of the ripped coffee from each plot was maintained with the mixture of fruit from the crop. The rest of the coffee was washed and separated in float and green/cherry fruits. The different coffees were placed on the drying yard till the water
\end{abstract}

INDEX TERMS: Coffee, reaper, chemical composition. content of $11 \%$ (w.b.). After drying, the coffee was processed and submitted to the following evaluation: polyphenol, total, reducing and non-reducing sugars, total soluble solids, total titrable acidity and cup proof. Considering the results obtained, in spite of significant differences was observed among the average values of polyphenol content, sugar content, soluble solids and titrable acidity, for the different mechanized harvest, it was not possible to establish a definite association between harvest system and chemical composition. It was not possible to distinguish on the basis of the cup proof, differences in coffee quality in terms of the harvest system because in all the samples analyzed the drink was classified as soft, only soft and hard.

1. Extraído da dissertação de Mestrado apresentada pelo primeiro autor à UNIVERSIDADE FEDERAL DE LAVRAS/UFLA, Caixa Postal 37 - 37200-000 - Lavras, MG.

2. Engenheiro Agrônomo, MSc., Ciência dos Alimentos/UFLA. cassiocj@hotmail.com

3. DSc., Professor Adjunto, DEG/UFLA. Fone: (35)3829-1488. borem@ufla.br

4. DSc., Professor Adjunto, DCA/UFLA. Fone: (35)3829-1405.

5. DSc., Professor Adjunto, DEG/UFLA. Fone: (35) 3829-1494. 


\section{INTRODUÇÃO}

O café de boa qualidade é aquele que apresenta bebida com bom aroma, bom corpo, boa acidez e suavidade, cor e aspecto homogêneos. Além disso, não deverá conter os defeitos verdes, verde-escuros, pretoverdes, ardidos e pretos.

Além das características inerentes ao próprio grão, a qualidade do café depende de diversos fatores, tais como a espécie ou cultivar, condição climática da região produtora, condução da lavoura e sistema de cultivo, número de florações e época de colheita, ataque de pragas e microorganismos, cuidados na pós-colheita e ocorrência de danificações mecânicas (PIMENTA, 2001; CARVALHO, 1998).

Por apresentar mais de uma florada, o cafeeiro tende a apresentar, num determinado momento da fase de maturação, frutos em diferentes estádios de maturação. Considerando a interferência que a presença dos diferentes tipos de café (verde, cereja e seco/passa) pode representar na composição química e na qualidade do produto, uma das principais dúvidas do cafeicultor é qual o momento ideal para se iniciar a colheita, sem que haja prejuízos na qualidade. Neste sentido, a quantidade de café ainda verde e a queda de frutos já secos são fatores a serem considerados para o início da colheita. Deve-se considerar como ideal, no máximo, $5 \%$ de verdes; porém, em anos de maturação muito desuniforme, toleram-se teores de até $20 \%$, o que prejudica a qualidade do café (VILELA e PEREIRA, 1998).

A colheita do café constitui-se de uma série de operações, que podem ser realizadas de maneiras distintas. Essas operações consistem nos seguintes sistemas de colheita manual, semimecanizado e mecanizado. Apesar de esse último sistema ser chamado de mecanizado, não dispensa totalmente o uso de serviço manual, pois as máquinas não conseguem colher todos os frutos da planta. A tendência que se verifica é a expansão do sistema semi-mecanizado, com o emprego equilibrado de mão-de-obra e máquinas (SILVA, 2001).

Em se tratando de mecanização, muito tem se falado das colhedoras de café. Existem, atualmente, diversos modelos destinados à execução dessa operação específica, como as máquinas que possuem motor costal ou lateral e que acionam hastes vibratórias manejadas manualmente denominadas de derriçadoras portáteis motorizadas, existindo modelos que derriçam, recolhem, abanam e ensacam o café colhido em uma única operação, como as conjugadas ou automotrizes (PÁDUA et al., 1999; SILVA, 2001).
Segundo Cruz Neto e Matiello (1981), a colheita do café é uma operação muito significativa na composição dos custos de produção. Ela é responsável, em média, por $30 \%$ do custo total e por cerca de $40 \%$ da mão-de-obra empregada nos tratos normais da lavoura cafeeira. Segundo Silva et al. (2001), a mecanização da colheita é um importante fator para reduzir o custo de produção do café, tendo em vista que essa redução é diretamente proporcional ao grau de mecanização das operações.

Além da comprovada eficiência na redução de mão-de-obra e dos custos operacionais, outros parâmetros, como índice de desfolha, tempo efetivo de derriça, eficiência e porcentagem de repasse também já foram avaliados (GROSSI, 1996; BARBOSA, 2001; GARCIA e FIORAVANTE, 2001; SILVA, 2001). Entretanto, parâmetros relacionados à qualidade do café colhido mecanicamente ainda não foram relatados.

Oficialmente a qualidade do café é avaliada por meio de análise sensorial (mais conhecida como prova de xícara) e classificação por tipo e peneira. Mas também são realizadas análises químicas capazes de auxiliar a avaliação da qualidade do café (BORÉM et al., 2001).

Os polifenóis são responsáveis pela adstringência dos frutos, interferindo no sabor do café. Existem indícios da ocorrência de maior concentração de polifenóis em cafés de pior qualidade. Isso tem sido atribuído ao estádio de maturação dos frutos, especialmente em razão de elevadas porcentagens de frutos verdes (CARVALHO et al., 1989; PIMENTA et al., 2000; PIMENTA, 2001) e da presença de defeitos (PEREIRA, 1997; COELHO, 2000).

O teor dos açúcares totais, redutores e nãoredutores é influenciado pelo estádio de maturação dos frutos, pelo ataque de microorganismos, local de cultivo, presença de defeitos, injúrias mecânicas (CARVALHO et al., 1989; LEITE, 1991; CHAGAS, 1994; PEREIRA, 1997; COELHO, 2000). Pimenta et al. (2000) observaram que ocorreu um aumento gradativo nos teores dos açúcares redutores à medida que a maturação dos frutos foi se intensificando, atingindo o valor máximo no café-cereja e, ainda, que quando os frutos secam na planta, os teores de açúcares diminuem.

Uma maior quantidade de sólidos solúveis é desejável, tanto do ponto de vista do rendimento industrial, como pela sua contribuição para assegurar o corpo da bebida, (LOPES, 2000).

Segundo trabalho realizado por Arcila-Pulgarin e Valência-Aristizabal (1975), o fruto de café no estádio 
de maturação verde possui menor acidez, aumentando à medida que o fruto intensifica seu processo de maturação. Essas observações foram confirmadas pelo trabalho realizado por Pimenta et al. (2000). Carvalho et al. (1989) relacionam a maior acidez em cafés de pior qualidade às fermentações ocorridas nos grãos, provavelmente com a ocorrência de microorganismos.

Tendo em vista a intensificação do uso da colheita mecanizada nas lavouras de café, e com o propósito de isolar o efeito da composição do lote em função do estádio de maturação dos frutos, com o presente trabalho buscou-se estudar a influência de seis sistemas de colheita na qualidade de bebida e na composição química de três tipos de café: cereja/verde e bóia (provenientes da lavagem do café) e no café composto pela mistura de frutos provenientes da lavoura.

\section{MATERIAL E MÉTODOS}

\section{Localização e caracterização do experimento}

Este trabalho foi desenvolvido na Fazenda Rancho Fundo, município de Campos Gerais, MG, e as análises químicas e sensoriais foram realizadas no Laboratório de Grãos e Cereais do Departamento de Ciência dos Alimentos da UFLA e no Laboratório de Qualidade do Café Dr. Alcides Carvalho do Centro Tecnológico do Sul de Minas da EPAMIG, em Lavras, MG.

Em uma lavoura de café (Coffea arabica L.) da cultivar Acaiá Cerrado, foram estudados seis sistemas de colheita: a) derriça manual no pano com recolhimento e abanação manuais; b) derriça manual no chão com recolhimento e abanação manuais; c) derriça mecanizada no pano com derriçadora portátil, com recolhimento e abanação manuais; d) derriça mecanizada no chão com derriçadora portátil, com recolhimento e abanação manuais; e) derriça mecanizada no chão com derriçadora portátil, com recolhimento e abanação mecanizados e f) derriça mecanizada com derriçadora automotriz. A colheita foi realizada quando a lavoura apresentava cerca de $20 \%$ de frutos verdes. Nos sistemas com derriça no chão, foi feita a varrição sob o cafeeiro antes que se realizasse a derriça.

As máquinas utilizadas na derriça do café foram: derriçadora automotriz modelo K-3, com velocidade de trabalho de 900 metros por hora e vibração de 850 ciclos por minuto e derriçadora portátil modelo STIHL SP80, com garras de três dedos, excentricidade da coroa de $10 \mathrm{~mm}$ e rotação máxima de $10.500 \mathrm{rpm}$. Para o recolhimento mecânico, foi utilizada uma recolhedora MAQ 6000, tracionada por um trator cafeeiro 4 x 2, com tração auxiliar, sendo acionada pela TDP a $540 \mathrm{rpm}$, operando com velocidade de 1.200 metros por hora.

Um terço do café derriçado de cada parcela foi levado diretamente da lavoura para o terreiro de secagem, constituindo o café-mistura. O restante do café foi lavado, separando-se os frutos em bóia e verde/cereja. Os frutos colhidos em cada parcela foram lavados e colocados no terreiro separadamente, no mesmo dia da colheita. A secagem foi realizada completamente em terreiro de alvenaria, mantendo a massa de frutos em torno de $5 \mathrm{~cm}$ de altura. O café foi revolvido de hora em hora durante o dia. Após atingir a meia-seca, com teor de água em torno de $30 \%$ (b.u.), os frutos foram cobertos com lona de polietileno preta durante a noite. Esse procedimento foi realizado até o café atingir teor de água em torno de $11 \%$ (b.u.).

As amostras da porção mistura, verde/cereja e bóia foram beneficiadas em um descascador de amostras Pinhalense modelo DRC-2 e submetidas às seguintes análises para a avaliação da qualidade:

\section{Polifenóis}

Os polifenóis foram extraídos pelo método de Goldstain e Swain (1963), utilizando como extrator o metanol $80 \%$ (U/V) e identificados de acordo com o método de Folin Denis, descrito pela AOAC (1990). Os resultados foram expressos em porcentagem.

\section{Açúcares totais, redutores e não-redutores}

Os açúcares totais redutores e não-redutores foram extraídos pelo método de Lane-Ennyon, citado pela AOAC (1990) e determinados pela técnica de Somogy, adaptada por Nelson (1944). Os resultados foram expressos em porcentagem.

\section{Sólidos solúveis totais}

Os sólidos solúveis totais foram determinados conforme normas da AOAC (1990). Os resultados foram expressos em porcentagem.

\section{Acidez titulável total}

A acidez titulável total foi determinada por titulação com $\mathrm{NaOH} 0,1 \mathrm{~N}$ de acordo com a técnica descrita na AOAC (1990). Os resultados foram expressos em ml de $\mathrm{NaOH} 0,1 \mathrm{~N}$ por $100 \mathrm{~g}$ de amostra. 


\section{Prova de xícara}

A análise de prova de xícara foi realizada seguindo o método oficial brasileiro de classificação do café pela bebida (IBC, 1977), pelo provador oficial do CTSM/EPAMIG, de Lavras, MG.

\section{Análise estatística}

O delineamento estatístico usado foi o fatorial inteiramente casualizado $(6 \times 3)$ com seis sistemas de colheita, três tipos de café e três repetições. Para a instalação do experimento no campo, escolheu-se um talhão homogêneo, onde foram sorteadas, ao acaso, dezoito parcelas para a aplicação dos seis sistemas de colheita com três repetições. Cada parcela tinha trinta metros de comprimento, com 36 plantas em uma mesma linha. Em seguida, cada uma das dezoito parcelas foi dividida para a obtenção do café-mistura, bóia e verde/cereja. Para comparação entre as médias, foi utilizado teste de StudentNewman-Keuls.

\section{RESULTADOS E DISCUSSÃO}

\section{Polifenóis}

Pela análise de variância dos teores médios de polifenóis, para o café colhido por seis sistemas de colheita nos cafés-mistura, bóia e verde/cereja, a interação entre o sistema de colheita e o tipo de café foi significativa a $1 \%$ de probabilidade $(\mathrm{P}<0,01)$. Observa-se na Tabela 1 que, apesar de terem ocorrido diferenças significativas $(\mathrm{P}<0,01)$ entre os teores médios de polifenóis para os diferentes sistemas de colheita e tipos de café, não há uma tendência definida que possa explicar essas diferenças.
Os teores de polifenóis encontrados neste trabalho são reduzidos e possivelmente não alteraram intensamente a qualidade da bebida. Apesar de terem sido observadas por Carvalho Júnior (2002) variações significativas na quantidade de frutos verdes, cereja e seco/passa entre os sistemas de colheita, não se pode precisar se essas diferenças foram suficientes para interferirem nos teores de polifenóis encontrados nas amostras estudadas.

\section{Açúcares totais e não-redutores}

Pela análise de variância dos teores médios de açúcares totais e de açúcares não-redutores de cafés colhidos por seis sistemas e três tipos de café, o sistema de colheita, o tipo de café e a interação do sistema de colheita com o tipo de café não foram significativos a $5 \%$ de probabilidade $(\mathrm{P}<0,05)$.

Apesar de terem sido observadas por Carvalho Júnior (2002) diferenças significativas na porcentagem de frutos verdes, cerejas e seco/passa, colhidos pelos diferentes sistemas, os teores de açúcares totais e nãoredutores não foram influenciados pelo sistema de colheita e nem pelo tipo de café. Foram encontrados teores médios variando, respectivamente, entre $9,70 \%$ a $7,20 \%$ e de $8,90 \%$ a $6,24 \%$, para os açúcares totais e não-redutores.

\section{Açúcares redutores}

Pela análise de variância dos teores médios de açúcares redutores em cafés colhidos por seis sistemas e três tipos de café, a interação entre o sistema de colheita e o tipo de café foi significativa $(\mathrm{P}<0,01)$.

TABELA 1 - Teores médios de polifenóis (\%) em cafés colhidos por seis sistemas e três tipos de café.

\begin{tabular}{lccc}
\hline \multirow{2}{*}{ Sistemas } & \multicolumn{3}{c}{ Tipos de café } \\
\cline { 2 - 4 } & Mistura & Bóia & Verde/cereja \\
\hline Derriça manual no pano e recolhimento manual & 4,92 ab B & 5,63 b A & 5,21 a B \\
Derriça manual no chão e recolhimento manual & 4,76 ab B & 5,57 b A & 5,23 a A \\
Derriça c/ derriçadora portátil no pano e recolhimento manual & 4,55 b B & 5,55 b A & 5,19 a A \\
Derriça c/ derriçadora portátil no chão e recolhimento manual & 4,69 ab B & 5,73 b A & 5,51 a A \\
Derriça c/ derriçadora portátil no chão e recolhimento mecânico & 4,49 b C & 6,12 ab A & 5,53 a B \\
Derriça c/ derriçadora Automotriz & 5,21 a B & 6,53 a A & 5,31 a B \\
\hline
\end{tabular}

Médias seguidas pela mesma letra minúscula na coluna e mesma letra maiúscula na linha não diferem entre si a $1 \%$ de probabilidade, pelo teste SNK.

Ciênc. agrotec., Lavras. V.27, n.5, p.1089-1096, set./out., 2003 
Na Tabela 2 encontram-se os teores médios de açúcares redutores em cafés colhidos por seis sistemas e três tipos de café. Quanto ao sistema de colheita no café-mistura, não ocorreram diferenças significativas $(\mathrm{P}<0,01)$. Entretanto, no bóia, o café derriçado com derriçadora portátil no chão com recolhimento manual apresentou maior teor de açúcares redutores do que os demais sistemas. No café verde/cereja, ocorreram diferenças, mas não seguiram uma tendência definida.

$\mathrm{Na}$ Tabela 2, apesar de não diferenciarem significativamente entre si $(\mathrm{P}<0,01)$, todas as médias foram sistematicamente maiores no bóia. Diferenças significativas $(\mathrm{P}<0,01)$ ocorreram apenas na derriça portátil com recolhimento manual. Entretanto, esperavam-se os menores valores desses açúcares no bóia. A diminuição dos açúcares pode ser atribuída a um início de senes- cência dos frutos, no qual os açúcares são metabolizados pela via anaeróbica com produção de ácidos e álcool. Como as condições climáticas foram favoráveis, pode não ter ocorrido fermentações indesejáveis, que também podem ser responsáveis pelo consumo desse açúcar.

\section{Sólidos solúveis totais}

Pela análise de variância dos teores médios de sólidos solúveis totais em cafés colhidos por seis sistemas e três tipos de café, a interação entre o sistema de colheita e o tipo de café não foi significativa $(\mathrm{P}<0,05)$. No entanto, foi significativa $(\mathrm{P}<0,05)$ para o sistema de colheita e para o tipo de café. Na Tabela 3 encontram-se os teores médios de sólidos solúveis totais em cafés colhidos por seis diferentes sistemas.

TABELA 2 - Teores médios de açúcares redutores (\%) em cafés colhidos por seis sistemas e três tipos de café.

\begin{tabular}{lccc}
\hline \multicolumn{1}{c}{ Sistemas } & \multicolumn{2}{c}{ Tipos de café } \\
\cline { 2 - 4 } & Mistura & Bóia & Verde/cereja \\
\hline Derriça manual no pano e recolhimento manual & 0,58 a A & 0,63 b A & 0,58 a A \\
Derriça manual no chão e recolhimento manual & 0,51 a A & 0,58 b A & 0,58 a A \\
Derriça c/ derriçadora portátil no pano e recolhimento manual & 0,52 a A & 0,56 b A & 0,49 ab A \\
Derriça c/ derriçadora portátil no chão e recolhimento manual & 0,48 a B & 0,75 a A & 0,45 b B \\
Derriça c/ derriçadora portátil no chão e recolhimento mecânico & 0,50 a A & 0,59 b A & 0,55 ab A \\
Derriça c/ derriçadora Automotriz & 0,56 a A & 0,61 b A & 0,59 a A \\
\hline
\end{tabular}

Médias seguidas pela mesma letra minúscula na coluna e mesma letra maiúscula na linha não diferem entre si a $1 \%$ de probabilidade, pelo teste SNK.

TABELA 3 - Teores médios de sólidos solúveis totais (\%) em cafés colhidos por seis sistemas.

\begin{tabular}{lc}
\hline \multicolumn{1}{c}{ Sistemas } & Valores médios \\
\hline Derriça manual no pano e recolhimento manual & 34,03 a \\
Derriça manual no chão e recolhimento manual & 34,58 a \\
Derriça c/ derriçadora portátil no pano e recolhimento manual & $35,28 \mathrm{a}$ \\
Derriça c/ derriçadora portátil no chão e recolhimento manual & $35,28 \mathrm{a}$ \\
Derriça c/ derriçadora portátil no chão e recolhimento mecânico & 35,28 a \\
Derriça c/ derriçadora Automotriz & 32,78 a \\
\hline
\end{tabular}

Médias seguidas pela mesma letra na coluna não diferem entre si a $5 \%$ de probabilidade, pelo teste SNK. 
Pela análise de variância, o sistema de colheita foi significativo $(\mathrm{P}<0,05)$. No entanto, observa-se na Tabela 3 que o teste de SNK, que foi utilizado para comparar as médias, não foi capaz de distinguir essas diferenças significativas $(\mathrm{P}<0,05)$.

Na Tabela 4 são apresentados os teores médios de sólidos solúveis totais em cafés mistura, bóia e verde/cereja. Observa-se que o teor de sólidos solúveis totais no café mistura foi significativamente $(\mathrm{P}<0,05)$ maior do que no café verde/cereja. O cafébóia não diferiu significativamente $(\mathrm{P}<0,05)$ dos cafés mistura e verde/cereja. Segundo Carvalho Júnior (2002), essas diferenças podem ter sido causadas pela elevada porcentagem de frutos secos/passas no café mistura.

TABELA 4 - Teores médios de sólidos solúveis totais (\%) em cafés colhidos por três tipos.

\begin{tabular}{lc}
\multicolumn{1}{c}{ Tipos de café } & Valores médios \\
\hline Mistura & $35,34 \mathrm{a}$ \\
Bóia & $34,65 \mathrm{ab}$ \\
Verde/cereja & $33,61 \mathrm{~b}$ \\
\hline
\end{tabular}

Médias seguidas pela mesma letra na coluna não diferem entre si a $5 \%$ de probabilidade, pelo teste SNK.

Em outros produtos vegetais, como frutos, observa-se que os açúcares totais são um dos principais compostos a influenciar no teor de sólidos solúveis. Entretanto, no presente trabalho, observa-se que não ocorreram diferenças significativas nos teores de açúcares totais, o que pode justificar essas diferenças tão pequenas nos teores de sólidos solúveis totais.

\section{Acidez titulável total}

Pela análise de variância dos valores médios de acidez titulável total em cafés colhidos por seis sistemas e três tipos de café, o sistema de colheita e a interação entre o sistema de colheita e o tipo de café não foram significativos. No entanto, o tipo de café foi significativo $(\mathrm{P}<0,01)$, com um coeficiente de variação de $9,02 \%$.
Observa-se, na Tabela 5, que o valor médio de acidez titulável total foi significativamente $(\mathrm{P}<0,01)$ maior no café-bóia do que em relação aos cafés-mistura e verdes/cereja. Esse maior valor de acidez titulável total no café-bóia pode ser relacionado com a baixa porcentagem de frutos verdes normalmente encontrada nesse tipo de café.

TABELA 5 - Valores médios de acidez titulável total (ml de Na OH/100gr. de amostra) em três tipos de cafés.

\begin{tabular}{lc}
\hline \multicolumn{1}{c}{ Tipos de café } & Valores médios \\
\hline Mistura & $130,56 \mathrm{~b}$ \\
Bóia & $143,75 \mathrm{a}$ \\
Verde/cereja & $125,69 \mathrm{~b}$ \\
\hline
\end{tabular}

Médias seguidas pela mesma letra na coluna não diferem entre si a $1 \%$ de probabilidade, pelo teste SNK.

\section{Prova de xícara}

Na Tabela 6 encontra-se a classificação pela prova de xícara com três repetições para os três tipos de cafés colhidos pelos seis sistemas. As três repetições da prova de xícara referem-se às repetições de campo dos diferentes sistemas de colheita e dos tipos de café, uma vez que esses resultados não são passiveis de se tirar média. Observa-se que há diferenças na classificação da bebida dos cafés colhidos pelos seis sistemas e três tipos de café; porém, não foi possível estabelecer uma relação clara entre a qualidade da bebida, o sistema de colheita e o tipo de café. No entanto, pode-se dizer que todos os cafés apresentaram boa classificação da bebida, pois não foi encontrada nenhuma bebida abaixo de dura, que é considerada como padrão para a exportação. Isso pode ter sido causado pelo clima favorável para a obtenção de café de boa qualidade.

De modo geral, tem-se observado que a análise sensorial (prova de xícara) tem trazido dúvidas quanto à classificação do café, quando comparada com a composição química do grão, dificultando, dessa maneira, as avaliações em trabalhos de pesquisa nos quais se necessita de dados mais conclusivos e passíveis de análise estatística (LEITE, 1991; CHAGAS, 1994). 
TABELA 6 - Classificação pela prova de xícara com três repetições em cafés colhidos por seis sistemas e três tipos de café.

\begin{tabular}{lccc}
\hline \multirow{2}{*}{ Sistemas } & \multicolumn{3}{c}{ Tipos de café } \\
\cline { 2 - 4 } & Mistura & Bóia & Verde/cereja \\
\hline Derriça manual no pano e recolhimento manual & $\mathrm{D} / \mathrm{ApM} / \mathrm{D}$ & $\mathrm{D} / \mathrm{D} / \mathrm{D}$ & $\mathrm{ApM} / \mathrm{ApM} / \mathrm{D}$ \\
Derriça manual no chão e recolhimento manual & $\mathrm{ApM} / \mathrm{D} / \mathrm{D}$ & $\mathrm{ApM} / \mathrm{D} / \mathrm{D}$ & $\mathrm{D} / \mathrm{ApM} / \mathrm{ApM}$ \\
Derriça c/ derriçadora portátil no pano e recolhimento manual & $\mathrm{D} / \mathrm{D} / \mathrm{D}$ & $\mathrm{ApM} / \mathrm{D} / \mathrm{D}$ & $\mathrm{D} / \mathrm{D} / \mathrm{ApM}$ \\
Derriça c/ derriçadora portátil no chão e recolhimento manual & $\mathrm{ApM} / \mathrm{ApM} / \mathrm{D}$ & $\mathrm{ApM} / \mathrm{D} / \mathrm{D}$ & $\mathrm{D} / \mathrm{D} / \mathrm{D}$ \\
Derriça c/ derriçadora portátil no chão e recolhimento mecânico & $\mathrm{D} / \mathrm{D} / \mathrm{ApM}$ & $\mathrm{ApM} / \mathrm{D} / \mathrm{D}$ & $\mathrm{ApM} / \mathrm{D} / \mathrm{ApM}$ \\
Derriça c/ derriçadora Automotriz & $\mathrm{D} / \mathrm{ApM} / \mathrm{ApM}$ & $\mathrm{ApM} / \mathrm{M} / \mathrm{ApM}$ & $\mathrm{ApM} / \mathrm{D} / \mathrm{D}$ \\
\hline
\end{tabular}

M - Bebida mole

ApM - Bebida apenas mole

D - Bebida dura

\section{CONCLUSÕES}

Considerando as condições em que foi conduzido este trabalho, pode-se concluir que:

a) O sistema de colheita não interferiu nos teores médios de açúcares totais e açúcares não-redutores do café;

b) Não se pôde precisar uma associação definida entre o sistema de colheita e os teores de polifenóis, açúcares redutores e sólidos solúveis totais dos grãos analisados;

c) O café-bóia apresentou um valor significativamente $(\mathrm{P}<0,01)$ maior de acidez titulável total, quando comparado ao café verde/cereja e café mistura;

d) Não foram encontradas diferenças quanto à qualidade da bebida do café entre os sistemas de colheita estudados.

e) Ocorreram amostras de café classificadas como de bebida dura, apenas mole e mole, independentemente do sistema de colheita.

\section{REFERÊNCIAS BIBLIOGRÁFICAS}

ARCILA-PULGARIM, J.; VALÊNCIAARISTIZABAL, G. Relación entre la actividad de la polifenoloxidase (PFO) y las pruebas bebidas del café. Cenicafé, Caldas, v. 26, n. 2, p. 55-71, 1975.

ASSOCIATION OF OFFICIAL ANALYTICAL CHEMISTS. Official methods of analysts of the
Association of Official Analytical Chemists. 15. ed. Washington, 1990.

BARBOSA, J. A. Avaliação técnica e econômica de um derriçador mecânico portátil. In: CONGRESSO BRASILEIRO DE PESQUISAS CAFEEIRAS, 27., 2001, Uberaba. Resumos... Rio de Janeiro: MAA/PROCAFÉ, 2001. p. 355-356.

BORÉM, F. M.; CARVALHO JÚNIOR, C. de; PEREIRA, R. G. F. A.; SILVA, F. M.; HORDOIN, P. R.; MORAES, A. R. Qualidade do café (Coffea arabica L.) colhido por seis diferentes sistemas e três épocas. In: SIMPÓSIO DE PESQUISAS CAFEEIRAS DO SUL DE MINAS, 2., 2001, Lavras. Anais... Lavras: UFLA, 2001. p. 222-235.

CARVAlHO, V. D. de. Cafeicultura empresarial: produtividade e qualidade. 1998. 73 f. Monografia (Especialização "Lato Sensu") - Universidade Federal de Lavras. Fundação de Apoio, Ensino, Pesquisa e Extensão, Lavras, 1998.

CARVALHO, V. D. de; CHALFOUM, S. M.; CHAGAS, S. J. R. Relação entre classificação do café pela bebida e composição físico-química, química e microflora do grão beneficiado. In: CONGRESSO BRASILEIRO DE PESQUISAS CAFEEIRAS, 15., 1989, Campinas. Resumos... Rio de Janeiro: IBC, 1989. p. 25-26. 
CARVALHO JÚNIOR, C. de. Efeito de sistemas de colheita na qualidade do café (Coffea arabica L.). 2002. 139 p. Dissertação (Mestrado em Ciências dos Alimentos) - Universidade Federal de Lavras, Lavras, 2002.

CHAGAS, S. J. de R. Caracterização química e qualitativa de cafés de alguns municípios de três regiões produtoras de Minas. 1994. 83 f. Dissertação (Mestrado em Ciência dos Alimentos) - Escola Superior de Agricultura de Lavras, Lavras, 1994.

COELHO, K. F. Avaliação química e sensorial da qualidade do café de bebida estritamente mole após a inclusão de grãos defeituosos. Lavras: UFLA, 2000. $96 \mathrm{p}$.

CRUZ NETO, F.; MATIELO, J. B. Estudo comparativo de rendimento de colheita entre cultivares Mundo Novo e Catuaí, em lavouras com diferentes níveis de produtividade. In: CONGRESSO BRASILEIRO DE PESQUISAS CAFEEIRAS, 9., 1981, São Lourenço. Anais... Rio de Janeiro: MA/PROCAFE, 1981. p. 329333

GARCIA, A. W. R.; FIORAVANTE, N. Avaliação operacional e econômica das principais derriçadoras de café portáteis. In: CONGRESSO BRASILEIRO DE PESQUISAS CAFEEIRAS, 27., 2001, Uberaba. Resumos... Rio de Janeiro: MAA/PROCAFÉ, 2001. p. 4042.

GOLDSTEIN, J. L.; SWAIN, T. Changes in tannins in ripening fruits. Phytochemistry, Oxford, v. 2, n. 4, p. 371-382, Dec. 1963

GROSSI, J. C. Avaliação do custo da colheita mecanizada em relação à manual, na região de Patrocínio-MG. In: CONGRESSO BRASILEIRO DE PESQUISAS CAFEEIRAS, 22., 1996, Águas de Lindóia. Resumos... Rio de Janeiro: MA/PROCAFE, 1996. p. 115-116.

INSTITUTO BRASILEIRO DO CAFÉ. Cultura do café no Brasil: manual de recomendações. 2. ed. Rio de Janeiro, 1977. 36 p.

LEITE, I. P. Influência do local de cultivo e do tipo de colheita nas características físicas, composição química do grão e qualidade do café (Coffea arabica L.). 1991. 135 f. Dissertação (Mestrado em Ciência dos
Alimentos) - Escola Superior de Agricultura de Lavras, Lavras, 1991.

LOPES, L. M. V. Avaliação da qualidade de grãos de café crus e torrados de cultivares de cafeeiro (Coffea arábica L.). 2000. 95 p. Dissertação (Mestrado em Ciências dos Alimentos) - Universidade Federal de Lavras, Lavras, 2000.

NELSON, N. A photometric adaptation of Somogy method for the determination of glucose. Journal of Biological Chemists, Baltmore, v. 153, n. 1, p. 375384, 1944.

PADUA, T. S.; SILVA, F. M.; QUEIROZ, D. P. Caracterização do sistema de colheita mecanizada do café no Sul de Minas Gerais. In: CONGRESSO BRASILEIRO DE PESQUISAS CAFEEIRAS, 25., 1999, Franca. Resumos... Rio de Janeiro: MAA/PROCAFÉ, 1999. p. 321-322.

PEREIRA, R. G. F. A. Efeito da inclusão de grãos defeituosos na composição química e qualidade do café (Coffea arábica L.) "estritamente mole". 1997. 96 p. Tese (Doutorado) - Universidade Federal de Lavras, Lavras, 1997.

PIMENTA, C. J. Época de colheita e tempo de permanência dos frutos à espera da secagem, na qualidade do café. 2001. 145 p. Tese (Doutorado em Química, Físico-Química e Bioquímica de Alimentos) Universidade Federal de Lavras, Lavras, 2001.

PIMENTA, C. J.; COSTA, L.; CHAGAS, S. J. de R. Peso, acidez, sólidos solúveis, açúcares e compostos fenólicos em café (Coffea arábica L.), colhidos em diferentes estádios de maturação. Revista Brasileira de Armazenamento, Viçosa, n. 1, p. 23-30, 2000. Edição Especial: café.

SILVA, F. M. Colheita do café mecanizada e semimecanizada. Lavras: UFLA, 2001. p. 88. (Boletim de Extensão).

VILELA, E. R.; PEREIRA, R. G. F. A. Armazenamento e processamento de produtos agrícolas: póscolheita e qualidade do café. In: CONGRESSO BRASILEIRO DE ENGENHARIA AGRÍCOLA, 27., 1998, Poços de Caldas. Anais... Poços de Caldas: [s.n.], 1998. p. 219-274. 